Check for updates

Cite this: Chem. Sci., 2019, 10, 10072

๑ All publication charges for this article have been paid for by the Royal Society of Chemistry

Received 20th May 2019

Accepted 11th September 2019

DOI: $10.1039 / \mathrm{c} 9 \mathrm{sc} 02467 \mathrm{k}$

rsc.li/chemical-science

\section{Caesium fluoride-mediated hydrocarboxylation of alkenes and allenes: scope and mechanistic insights $\uparrow$}

\author{
Ashot Gevorgyan, (D) $\ddagger^{\mathrm{a}}$ Marc F. Obst, (D) $\ddagger^{\mathrm{b}}$ Yngve Guttormsen, ${ }^{\mathrm{a}}$ Feliu Maseras, (D) ${ }^{\mathrm{c}}$ \\ Kathrin H. Hopmann (iD *b and Annette Bayer (iD *a
}

\begin{abstract}
A caesium fluoride-mediated hydrocarboxylation of olefins is disclosed that does not rely on precious transition metal catalysts and ligands. The reaction occurs at atmospheric pressures of $\mathrm{CO}_{2}$ in the presence of 9 -BBN as a stoichiometric reductant. Stilbenes, $\beta$-substituted styrenes and allenes could be carboxylated in good yields. The developed methodology can be used for preparation of commercial drugs as well as for gram scale hydrocarboxylation. Computational studies indicate that the reaction occurs via formation of an organocaesium intermediate.
\end{abstract}

\section{Introduction}

$\mathrm{CO}_{2}$ provides a sustainable source of carbon that increasingly is being used in chemical synthesis. ${ }^{1}$ Construction of anthropogenic chemical carbon cycles $^{2}$ by valorisation of $\mathrm{CO}_{2}$ into chemicals, materials, and fuels, is a promising strategy for replacing fossil carbon in the chemical industry. ${ }^{1,3}$ Various studies have shown that transition metal-based catalysts are able to selectively reduce $\mathrm{CO}_{2}$ into simple chemicals, such as formic acid, methanol, alkanes, and $\mathrm{CO}^{3 a} \mathrm{CO}_{2}$ can also be incorporated into carbonates, which are valuable starting materials for polymer science. ${ }^{3 b}$ Use of $\mathrm{CO}_{2}$ in $\mathrm{C}-\mathrm{C}$ bond forming reactions opens new pathways towards value-added products and pharmaceuticals from $\mathrm{CO}_{2} \cdot{ }^{4}$

As part of our research interest to develop $\mathrm{C}-\mathrm{CO}_{2}$ bond forming reactions, ${ }^{5}$ we became interested in the coppercatalysed hydrocarboxylation reactions reported by Hou, ${ }^{6 a}$ Sawamura $^{6 b}$ and Skrydstrup ${ }^{6 c}$ (Scheme 1A). In these formal hydrocarboxylations, an initial hydroboration with 9-borabicyclo[3.3.1]nonane (9-BBN) transforms an alkene to an organoborane, which in a subsequent copper-catalysed step is carboxylated with $\mathrm{CO}_{2}$. In order to elucidate the mechanistic details of the carboxylation step, we embarked on a computational study of the reaction. Surprisingly, our

\footnotetext{
${ }^{a}$ Department of Chemistry, UiT The Arctic University of Norway, Norway. E-mail: annette.bayer@uit.no

${ }^{b}$ Hylleraas Centre for Quantum Molecular Sciences, Department of Chemistry, UiT The Arctic University of Norway, Norway. E-mail: kathrin.hopmann@uit.no

'Institute of Chemical Research of Catalonia (ICIQ), Spain

$\dagger$ Electronic supplementary information (ESI) available. See DOI: 10.1039/c9sc02467k

\$ These authors contributed equally.
}

computational analysis indicated the existence of a feasible carboxylation pathway that does not involve the copper complex. Our subsequent experiments confirmed that it is possible to carboxylate in situ formed organoboranes in absence of copper. Related reports of carboxylations with $\mathrm{CO}_{2}$ in absence of transition metals include fluoride-mediated carboxylations of organosilanes ${ }^{7 b-f}$ and $\mathrm{KO} t \mathrm{Bu}-\mathrm{mediated}$ carboxylations of benzylboronic esters (Scheme 1B). ${ }^{7 a}$ However, none of these reports addressed a possible role of the counterion for the observed reactivity. To the best of our knowledge, a CsF-mediated hydrocarboxylation with in situ generated organoboranes has not been reported. In the following, we detail our findings of the CsF-mediated hydrocarboxylation of alkenes with $\mathrm{CO}_{2}$ (Scheme 1C). A detailed computational analysis indicates that the reaction proceeds via formation of organocaesium intermediates. The described transformation expands the repertoire of carboxylation

(A) Hou, Sawamura, Skrydstrup

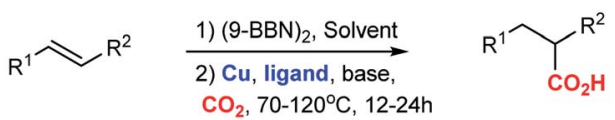

(B) Sato, Cantat, Kondo

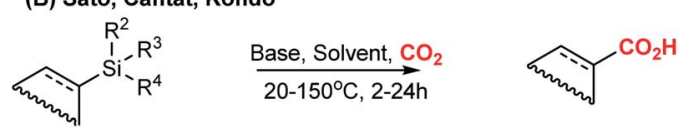

(C) Present approach

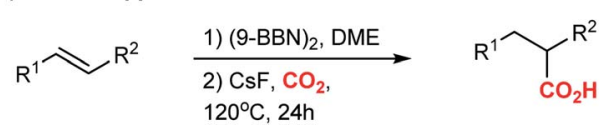

Scheme 1 Previous works $\left(A^{6}\right.$ and $\left.B^{7}\right)$ and present study (C). 
reactions that can be performed without the use of transition metal catalysts.

\section{Results and discussion}

On basis of a preliminary computational investigation of the hydrocarboxylation of alkenes, we speculated that trans-stilbene 1a can be hydrocarboxylated via an organoborane intermediate in the absence of a transition metal catalyst, which is in contrast to previous reports. ${ }^{6}$ To test our hypothesis, we used 9-BBN in dioxane to convert 1a into an organoborane intermediate, which we attempted to carboxylate with $\mathrm{CO}_{2}$ in a CsF-mediated transformation (Table 1). Gratifyingly, the corresponding carboxylic acid 2 a was obtained in $83 \%$ yield (Table 1, entry 2). In comparison, the previously reported copper-catalysed reaction $^{6 c}$ gave the carboxylation product $\mathbf{2 a}$ in $78 \%$ yield (Table 1, entry 1). The higher yield in absence of copper was observed for several substrates (ESI, Scheme S1 and S2 $\dagger$ ). This phenomenon may be explained by a copper-promoted decarboxylation reaction slowly consuming the product $2 \mathbf{a}^{\mathbf{8}}$ To support this hypothesis, we mixed 2-phenylpropionic acid with the $\mathrm{Cu}$ complex under reaction conditions, which lead us to recover only $95 \%$ of the starting acid, while in the absence of $\mathrm{Cu}$, the recovery of acid was $99 \%$ (ESI, Scheme S1†).

We proceeded to establish the optimum reaction conditions of the base-mediated carboxylation reaction. Screening of

Table 1 Optimization of reaction conditions ${ }^{a}$
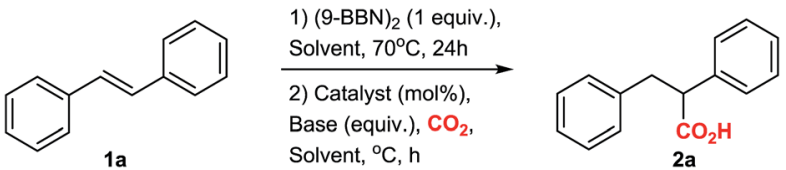

\begin{tabular}{|c|c|c|c|c|c|}
\hline Entry & Catalyst (mol\%) & Base (equiv.) & Solvent & ${ }^{\circ} \mathrm{C} / \mathrm{h}$ & ${ }^{b}$ Yield $\%$ \\
\hline 1 & $\operatorname{IPrCuI}(5)^{c}$ & $\operatorname{CsF}(3)$ & Dioxane & $120 / 24$ & 78 \\
\hline 2 & - & $\operatorname{CsF}(3)$ & Dioxane & $120 / 24$ & 83 \\
\hline 3 & - & $\operatorname{CsF}(3)$ & THF & $120 / 24$ & 61 \\
\hline 4 & - & $\operatorname{CsF}(3)$ & Diglyme & $120 / 24$ & 67 \\
\hline 5 & - & $\operatorname{CsF}(3)$ & DME & $120 / 24$ & 87 \\
\hline 6 & - & $\operatorname{CsF}(3)$ & DMA & $120 / 24$ & 0 \\
\hline 7 & - & $\operatorname{CsF}(3)$ & Toluene & $120 / 24$ & 70 \\
\hline 8 & - & $\operatorname{CsF}(3)$ & $\mathrm{MeCN}$ & $120 / 24$ & 0 \\
\hline 9 & - & $\mathrm{KF}(3)$ & DME & $120 / 24$ & 50 \\
\hline 10 & - & $\mathrm{NaF}(3)$ & DME & $120 / 24$ & 0 \\
\hline 11 & - & $\mathrm{Cs}_{2} \mathrm{CO}_{3}(3)$ & DME & $120 / 24$ & 71 \\
\hline 12 & - & $\mathrm{K}_{2} \mathrm{CO}_{3}(3)$ & DME & $120 / 24$ & 67 \\
\hline 13 & - & $\mathrm{KO} t \mathrm{Bu}(3)^{d}$ & DME & $120 / 24$ & 47 \\
\hline 14 & - & $\operatorname{CsF}(2)$ & DME & $120 / 24$ & 57 \\
\hline 15 & - & $\operatorname{CsF}(3)$ & DME & $80 / 24$ & 59 \\
\hline 16 & - & $\operatorname{CsF}(3)$ & DME & $120 / 28$ & 85 \\
\hline
\end{tabular}

${ }^{a}$ Reaction conditions: (1) 1a $(0.444 \mathrm{mmol}),(9-\mathrm{BBN})_{2}$ (1 equiv.), solvent $(3 \mathrm{~mL}), 70{ }^{\circ} \mathrm{C}, 24 \mathrm{~h}$. (2) (IPrCuI $\left.(5 \mathrm{~mol} \%)\right)$, base (2-3 equiv.), $\mathrm{CO}_{2} 120$ $\mathrm{mL}, 80-120{ }^{\circ} \mathrm{C}, 24-28 \mathrm{~h} .{ }^{b}$ Isolated yields. ${ }^{c}$ The active catalyst was prepared in situ (IPr $=1,3$-bis(2,6-diisopropylphenyl)imidazol-2ylidene). ${ }^{d}$ The reaction mixture was run at $20{ }^{\circ} \mathrm{C}$ for $30 \mathrm{~min}$ before addition of $\mathrm{CO}_{2}$. different solvents revealed that the reaction works well in ethers. The best yield was observed in dimethoxyethane (DME, 87\%, Table 1, entry 5). The screening of different bases indicated that the optimal base is CsF ( $87 \%$ yield; Table 1, entry 5), while other fluoride containing bases like $\mathrm{KF}$ and $\mathrm{NaF}$ gave inferior results (50\% and $0 \%$ yield, entry 9 and 10). Interestingly, also $\mathrm{Cs}_{2} \mathrm{CO}_{3}$ and $\mathrm{K}_{2} \mathrm{CO}_{3}$ gave good results ( $71 \%$ and $67 \%$ yield, entry 11 and 12), showing that not only the fluoride anion is important for the outcome of the reaction. On basis of the reports by $\mathrm{Hou}^{6 a}{ }^{6}$ Sawamura $^{6 b}$ and Schomaker, ${ }^{7 a}$ we also attempted to employ alkoxides as base, but observed difficulties in our system. If mixed simultaneously, the reaction between alkoxide and $\mathrm{CO}_{2}$ lead to the corresponding carbonates, and no carboxylation product was formed. Alkoxide bases were effective only if the second reaction step was run without $\mathrm{CO}_{2}$ for minimum 30 minutes at $20{ }^{\circ} \mathrm{C}$, followed by addition of $\mathrm{CO}_{2}$, which provided a yield of $47 \%$ (Table 1, entry 13). Further screening related to the stoichiometry of reagents, duration of the reaction, and temperature showed that the best conditions are 1 equiv. olefin and $(9-B B N)_{2}$ and 3 equiv. CsF in DME at $120^{\circ} \mathrm{C}$ for $24 \mathrm{~h}$ (Table 1 , entry 5 ; for further details see ESI, Table S1†).

With the optimized conditions at hand, we explored the substrate scope of the reaction (Scheme 2; ESI Scheme S3†). Screening of different substrates showed that the CsF-mediated hydrocarboxylation works only on systems where the in situ hydroboration step (mediated by 9-BBN) generates benzylic or allylic borane intermediates. Indeed, styrene and cyclohexene were not reactive under optimal conditions (ESI Table S1 $\dagger$ ). On the other hand, stilbenes, $\beta$-substituted styrenes and allenes were successful substrates. Neither the pinacol ester of benzylboronic acid nor in situ-generated benzylic catechol esters (instead of the organoborane intermediate) were reactive in the CsF-mediated carboxylation (ESI Scheme S4 †).

The CsF-mediated hydrocarboxylation of stilbene derivatives (1a-e) produced the corresponding carboxylic acids 2a-e with moderate to excellent yields (Scheme 2A). The conversion of (E)$\alpha$-methyl stilbenes $(\mathbf{1 d}, \mathbf{1 e})$ was regioselective, providing exclusive carboxylation at the sterically less hindered $\beta$-position and resulting in formation of $\mathbf{2 d}$ and $\mathbf{2 e}$, each as a mixture of diastereomers. The observed regioselectivity is assumed to be controlled by steric effects. ${ }^{6,9,10}$

The CsF-mediated hydrocarboxylation of $\beta$-substituted styrenes $(\mathbf{1} \mathbf{f}-\mathbf{l})$ gave the $\alpha$-carboxylated products $\mathbf{3 a - g}$ as the sole product in moderate to good yields (Scheme 2B). Interestingly, whereas the selectivity of the 9-BBN-initiated hydroboration of $\beta$-substituted styrenes is substrate-dependent and generally gives a non-regioselective mixture of boranes, ${ }^{6,9,10}$ our baseinitiated carboxylation appears to convert only the benzylic boranes, providing a single carboxylation product with excellent regioselectivity for $\mathbf{3 a - g}$ (Scheme 2B). In contrast, the $\mathrm{Cu}^{-}$ catalysed hydrocarboxylation does not differentiate between the regioisomeric borane intermediates, giving a mixture of carboxylic acids. ${ }^{6 c}$ For example, in the copper-catalysed hydrocarboxylation of indene (1k), we observed a mixture of $\alpha$ - and $\beta$ regioisomers with a ratio of $4: 1$ (ESI, Scheme S2 †).

Allenes also proved to be suitable substrates for CsFmediated hydrocarboxylation (Scheme 2C). Both aliphatic and 


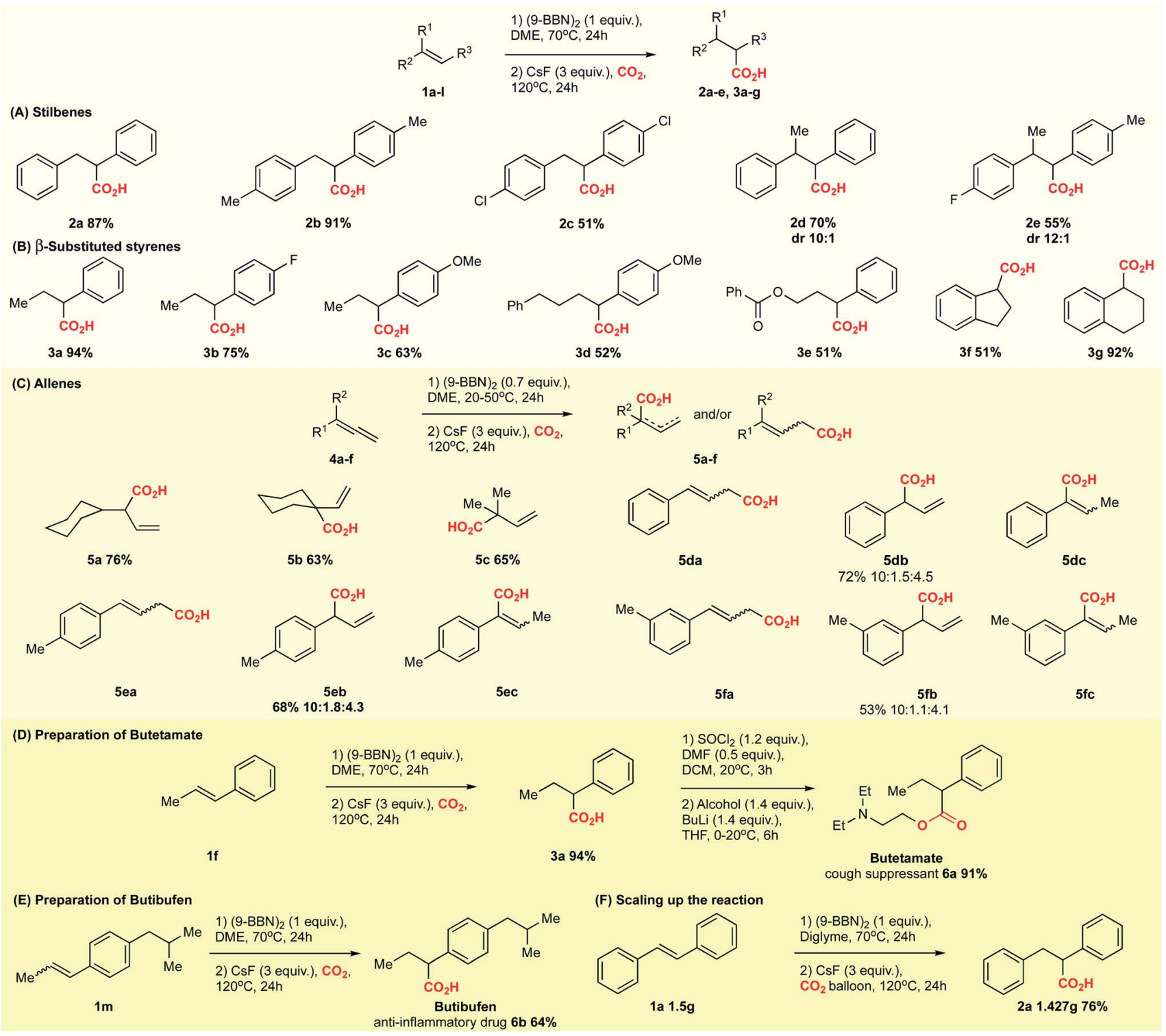

Scheme 2 Substrate scope of the CsF-mediated hydrocarboxylation.

aromatic allenes could be transformed to carboxylic acids 5a-f with good yields. The regioselectivity of the reaction was strongly dependent on the nature of the allene substituents. Allenes with aliphatic substituents gave the internal allylic carboxylic acid as a single product $\mathbf{5 a - c}$ (Scheme 2C). In contrast, allenes possessing aromatic substituents yielded the carboxylic acids $\mathbf{5 d - f}$ as isomeric mixtures, with the terminal carboxylic acids as the major product (Scheme 2C). Although borane-mediated hydroboration of allenes has been described ${ }^{11}$ the selectivity is not well understood, and equilibria of internal and terminal allylic boranes have been proposed. Recently, Chida and Sato showed that the hydroboration of allenes in deuterated THF occurs predominantly at the terminal double bond. ${ }^{11 f}$ Carboxylation of alkyl allenes may then proceed from the terminal allylic borane with an allyl shift, or involve the internal allylic borane generated through equilibration. For aryl allenes, the direct carboxylation of the terminal allylic borane is preferred as the system is less likely to rearrange due to conjugation.

We further tested the possibility of asymmetric hydrocarboxylation using the (-)-isopinocampheylborane TMEDA complex - a chiral analogue of 9-BBN - in the initial hydroboration step (ESI Scheme S5 $\dagger$ ). ${ }^{12}$ Even though the hydroboration-oxidation of trans- $\beta$-methylstyrene gave the corresponding alcohol with $36 \%$ ee (ESI, Scheme S5A $\dagger$ ), the hydroboration-carboxylation using our conditions led to racemic product (ESI, Scheme $\mathrm{S} 5 \mathrm{~B} \dagger$ ). The observed racemisation may be explained by the structural instability of intermediate organometallic compounds, such as the organoborane or an organocaesium (vide infra) at elevated temperatures. ${ }^{13}$ 
In order to show the versatility of the developed CsFmediated hydrocarboxylation reaction, we applied our strategy in the synthesis of the commercial drugs butetamate $6 \mathbf{a}$ and butibufen $\mathbf{6 b}$ from $\beta$-substituted styrenes (Scheme 2D and E). Although in case of butetamate, four steps are required (hydroboration, carboxylation, preparation of acid anhydride, and esterification), only two isolations were needed, providing almost quantitative yields. Similarly, butibufen was obtained in $64 \%$ yield using the direct hydrocarboxylation of $\beta$-substituted styrene $\mathbf{1 m}$ (Scheme 2E).

Importantly, the hydrocarboxylation reaction can be scaled up (Scheme 2F). For this we changed the solvent from DME to diglyme (2-methoxyethyl ether), which has a higher boiling point, allowing the reaction to be performed in simple flasks using a $\mathrm{CO}_{2}$ balloon. Starting from $1.5 \mathrm{~g}$ of stilbene, we could prepare $1.427 \mathrm{~g}$ of the corresponding acid $2 \mathrm{a}$ (Scheme $2 \mathrm{~F}$ ). The yield at gram scale $(76 \%$, Scheme 2$)$ is slightly larger compared to the small scale ( $67 \%$, Table 1 , entry 4$)$, probably due to better recovery of material during work-up at larger scale.

The computational analysis of the CsF-mediated carboxylation of in situ generated organoboranes provided insights into the mechanistic steps. Three boranes were included in the theoretical study (Fig. 1): b1 and b2, derived from the experimentally reactive alkenes trans-stilbene (1a) and trans- $\beta$-methylstyrene (1f), and b3, corresponding to the non-reactive alkene cyclohexene (10). Three possible reaction mechanisms (referred to as $\mathbf{A}, \mathbf{B}$ and $\mathbf{C}$ ) were found by an automated search of the potential energy surface with the AFIR method. ${ }^{14}$ Mechanism A (ESI, Fig. S6 $\dagger$ ) is characterized by a nucleophilic attack of the reactive carbon of the borane on a $\mathrm{CO}_{2}$ molecule, followed by a transmetalation with CsF. This mechanism is considered not viable, as all the evaluated boranes show a computed Gibbs free activation energy of $>50 \mathrm{kcal} \mathrm{mol}^{-1}$ for the first step (ESI, Table $\mathrm{S} 2 \dagger)$.

Reaction mechanism B (Scheme 3) occurs through two steps: First, the formation of a B-F bond between the borane io and a CsF molecule yielding intermediate i1, and second, the nucleophilic attack of intermediate $\mathbf{i 1}$ on $\mathrm{CO}_{2}$. The latter step is characterized by a concerted formation of the $\mathrm{C}-\mathrm{CO}_{2}$ bond and the cleavage of the $\mathrm{B}-\mathrm{C}$ bond, releasing $\mathrm{F}-(9-\mathrm{BBN})$ and forming the product $\mathbf{p 1}$. The overall barrier computed for the different boranes with mechanism B (ESI, Table S3†) is significantly lower than with mechanism $\mathbf{A}$ (Table $\mathrm{S} 2 \dagger$ ). However, with values

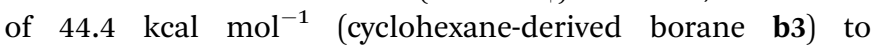
$52.3 \mathrm{kcal} \mathrm{mol}^{-1}$ (trans- $\beta$-methylstyrene-derived borane b2), the barriers are too high to be overcome at the reaction temperature of $120{ }^{\circ} \mathrm{C}^{15}$

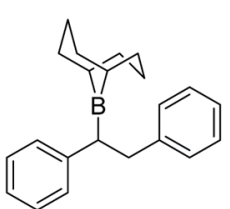

b1

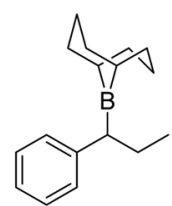

b2

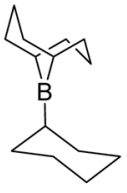

b3
Fig. 1 Computationally investigated boranes.

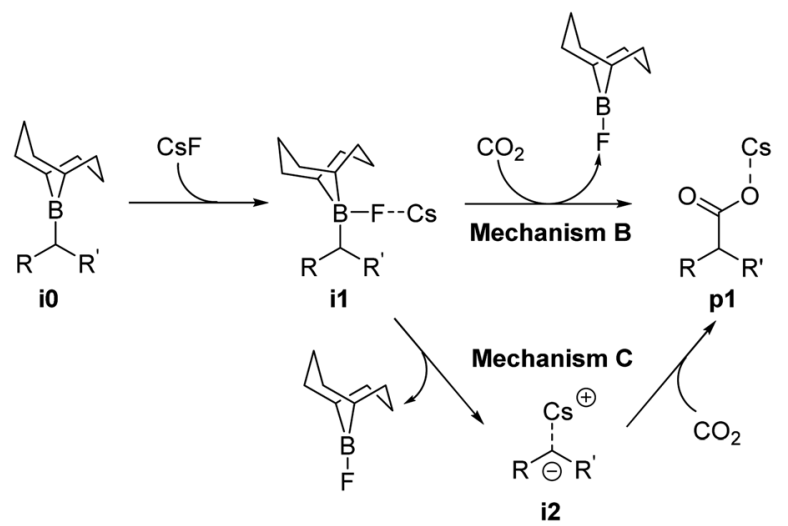

Scheme 3 Computed reaction mechanisms B and C.

The first step of mechanism $\mathbf{C}$ (Scheme 3) is the same as for $\mathbf{B}$, the formation of intermediate i1. In the next step, the boroncarbon bond is cleaved, releasing a F-(9-BBN) molecule and forming the organocaesium intermediate i2 (Fig. 2). In the final step, i2 undergoes a nucleophilic attack on a $\mathrm{CO}_{2}$ molecule. Interestingly, at the insertion TS for substrate $\mathbf{b} 1, \mathrm{CO}_{2}$ shows no clear preference to interact with the cesium centre (Fig. 2; see also ESI, Fig. S9†), in contrast to other computational studies predicting $\mathrm{CO}_{2}-\mathrm{Cs}$ interactions. ${ }^{16}$ However, for $\mathbf{b} 2$, a preference for a weak $\mathrm{CO}_{2}-\mathrm{Cs}$ interaction is seen (ESI, Fig. S10†). The reason may be that the $\mathrm{Cs}$ atom experiences stronger interactions with the two phenyl rings of b1 than with the single aromatic ring in b2, making additional $\mathrm{CO}_{2}-\mathrm{Cs}$ interactions preferable for $\mathbf{b} 2$.

For boranes b1 and b2, the rate-limiting step of mechanism $\mathrm{C}$ is the cleavage of the boron-carbon bond with overall barriers of $34.0 \mathrm{kcal} \mathrm{mol}{ }^{-1}$ for borane $\mathbf{b 1}$ (derived from trans-stilbene) and $36.7 \mathrm{kcal} \mathrm{mol}^{-1}$ for $\mathbf{b 2}$ (derived from trans- $\beta$-methylstyrene). Mechanism $\mathbf{C}$ is thus the preferred pathway for boranes $\mathbf{b} \mathbf{1}$ and b2. The full energy profile for carboxylation of b1 via mechanism $\mathrm{C}$ is shown in Fig. 3.

For borane b3 (derived from cyclohexene), the rate-limiting step of mechanism $\mathbf{C}$ is the $\mathrm{C}-\mathrm{CO}_{2}$ bond formation with an overall barrier of $51.5 \mathrm{kcal} \mathrm{mol}^{-1}$, which is not feasible. The lowest computed barrier for borane $\mathbf{b 3}$ is thus observed with mechanism B (Fig. 3), which at $44.4 \mathrm{kcal} \mathrm{mol}^{-1}$ is not feasible at

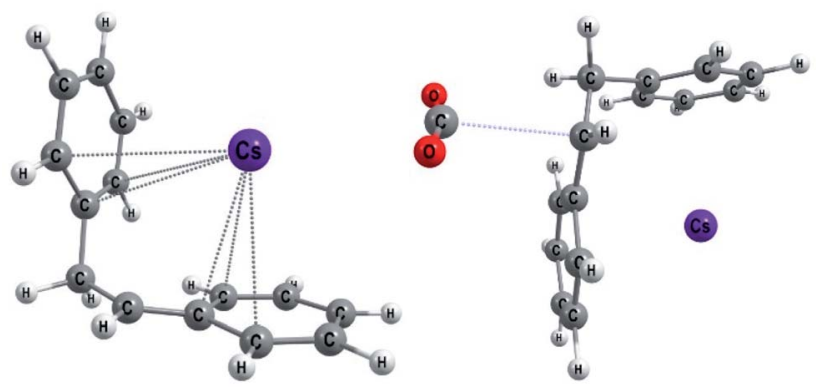

Fig. 2 Optimized geometries for b1 (Mechanism C): the organocaesium intermediate i2 (left) and the $\mathrm{C}-\mathrm{CO}_{2}$ bond formation $\mathrm{TS}\left(\mathrm{TS}_{\mathrm{i} 2-}\right.$ p1, right). 


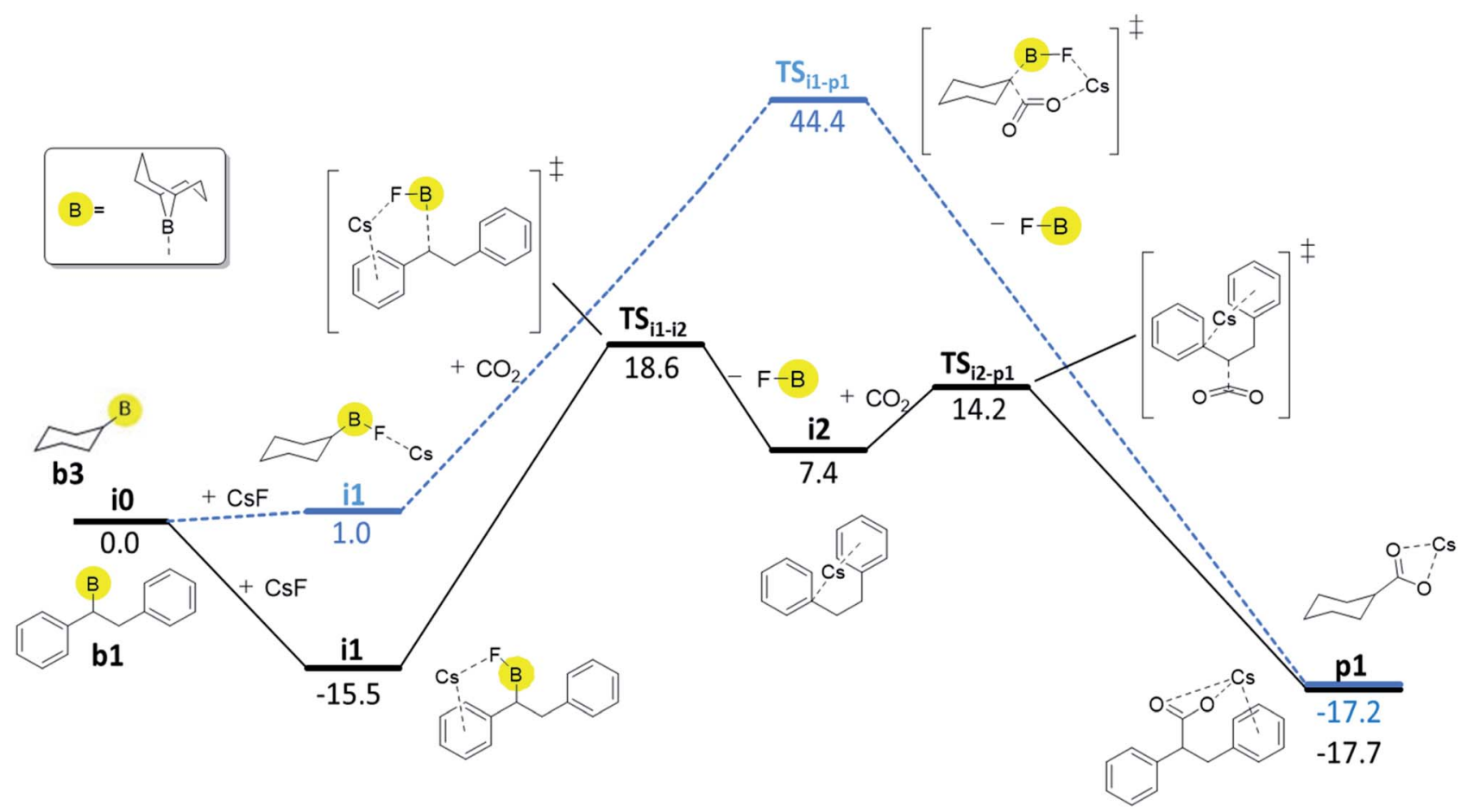

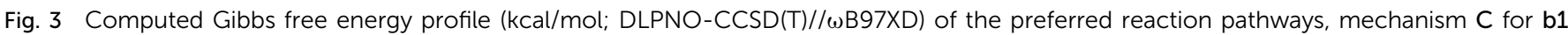
(black solid line) and mechanism B for b3 (blue dashed line).

the experimental temperature, in line with the experimentally observed lack of reactivity of cyclohexene.

Our computational and experimental results are in good agreement, indicating that the carboxylation of benzylic boranes occurs via reaction mechanism $\mathbf{C}$, which features an organocaesium intermediate i2. The benzylic boranes $\mathbf{b} \mathbf{1}$ and $\mathbf{b} \mathbf{2}$ are able to stabilize the organocaesium intermediate i2 via delocalization of the negative charge, and via cation- $\pi$ interactions between caesium and the aromatic substituents on the organoborane. Similar Cs- $\pi$ interactions have been observed in related computational studies. ${ }^{17}$ The cost of forming i2 is only $7.4 \mathrm{kcal} \mathrm{mol}^{-1}$ for $\mathbf{b 1}$ and $12.7 \mathrm{kcal} \mathrm{mol}^{-1}$ for b2. The cyclohexyl borane $\mathbf{b} 3$ lacks these stabilizing effects, resulting in a relative energy of $37.2 \mathrm{kcal} \mathrm{mol}^{-1}$ for the i2 intermediate. We therefore suggest that the stability of the organocaesium intermediate i2 is the factor determining the reactivity of olefins in the CsFmediated hydrocarboxylation.

\section{Conclusions}

We report a CsF-mediated hydrocarboxylation of alkenes and allenes proceeding via a hydroboration with 9-BBN followed by a CsF-mediated carboxylation of the resulting organoboranes. The caesium fluoride-mediated carboxylation was effective for in situ generated benzylic and allylic organoboranes derived from stilbenes, $\beta$-substituted styrenes and allenes, providing the corresponding carboxylic acids with good yields and excellent regioselectivities. The developed methodology was demonstrated at gram-scale and was used for the production of commercial drugs. Computational studies indicate that benzylic organoboranes are transformed to organocaesium intermediates, which then undergo a nucleophilic attack on $\mathrm{CO}_{2}$. Stabilisation of the organocaesium intermediate by the aromatic substituent account for the observed selectivity towards benzylic organoboranes.

\section{Methods}

Experimental and computational details are given in the ESI. $\dagger$ The ESI includes experimental procedures and analytical data, an example input for DLPNO-CCSD(T) calculations, computed energies for the full reaction pathways for $\mathbf{b} \mathbf{1}, \mathbf{b} \mathbf{2}$ and $\mathbf{b} 3$, and a comparison of computed $\mathrm{C}-\mathrm{CO}_{2} \mathrm{TS}$ structures. A separate xyz file contains all optimized coordinates in a format that allows easy visualization with Mercury.

\section{General procedure for metal-free hydrocarboxylation of stilbenes, $\beta$-substituted styrenes and allenes}

Inside the glove box, a $45 \mathrm{~mL}$ pressure tube was charged with the corresponding olefin or allene $(1.5 \mathrm{mmol}),(9-\mathrm{BBN})_{2}(1$ equiv. for olefins or 0.7 equiv. for allenes) and dry DME $(7 \mathrm{~mL})$. The flask was closed with a suitable cap, removed from the glove box and heated to $70^{\circ} \mathrm{C}$ (olefin) or $50{ }^{\circ} \mathrm{C}$ (allene) for $24 \mathrm{~h}$. Afterwards, the pressure tube was transferred back to the glove box. To the reaction mixture at $20^{\circ} \mathrm{C}$ was added $\mathrm{CsF}$ (3 equiv.). The pressure tube was closed with the cap and removed from the glove box. Afterwards $\mathrm{CO}_{2}(120 \mathrm{~mL})$ was added via a syringe, which was followed by stirring of the reaction mixture at $120{ }^{\circ} \mathrm{C}$ for $24 \mathrm{~h}$. Next, the reaction mixture was 
diluted with $30 \mathrm{~mL} \mathrm{Et}{ }_{2} \mathrm{O}$ and transferred into a $500 \mathrm{~mL}$ separating funnel. The resulting mixture was extracted with $30 \mathrm{~mL}$ saturated basic $\left(\mathrm{NaHCO}_{3}, 1 \mathrm{M} \mathrm{KOH}\right)$ solution (3 times). The resulting basic solution was washed with $15 \mathrm{~mL} \mathrm{Et}_{2} \mathrm{O}$ (once), acidified (50-55 $\mathrm{mL} 6 \mathrm{M} \mathrm{HCl}$ ) and extracted with $30 \mathrm{~mL} \mathrm{Et}_{2} \mathrm{O}$ (3 times). The resulting solution of $\mathrm{Et}_{2} \mathrm{O}$ was distilled to dryness to give the corresponding acid (in case of $\mathbf{5 c}$ the final solution of $\mathrm{Et}_{2} \mathrm{O}$ was dried using $\mathrm{Na}_{2} \mathrm{SO}_{4}$, which was followed by careful evaporation of solvents).

\section{Computational methods}

Density functional theory (DFT) calculations were performed with the $\omega$ B97XD hybrid functional, ${ }^{18}$ as implemented in Gaussian 16, Revision B.01. ${ }^{19}$ Geometries were optimized with the SDD ECP and basis set for Cs and the $6-31+\mathrm{G}^{*}$ basis set for all other elements. Initial guess structures for the transition states were obtained through linear transit calculations and through artificial force induced reaction modelling (AFIR) as implemented in GRRM. ${ }^{14}$ Solvation effects were included in the final geometry optimizations via the IEFPCM model (1,4dioxane). Explicit solvent molecules may bind to specific points in the system, but we do not expect them to affect the overall mechanistic picture, ${ }^{17}$ and because of this they were omitted from the calculation. Vibrational, entropic, and temperature corrections were computed at 393.15 Kelvin, with the same level of theory as geometry optimizations. Electronic energies were obtained with DLPNO-CCSD $(\mathrm{T})^{20}$ using ORCA 4.1.1. ${ }^{21}$ The ZORA operator as well as the basis sets SARC-ZORA-TZVPP (for Cs) and ZORA-def2-QZVPP (all other elements) were employed. The final Gibbs free energies $\left(\Delta G_{\text {DPLNO-CCSD(T)/ } / \omega \mathrm{B} 97 \mathrm{XD}}\right)$ in the main text correspond to the DLPNO-CCSD(T) electronic energies combined with the DFT-based vibrational, entropic and temperature corrections, and the standard state (SS, 393.15 K) conversion in case of a change in the number of moles: ${ }^{22}$ $\Delta G_{\mathrm{DPLNO}-\mathrm{CCSD}(\mathrm{T}) / / \omega \mathrm{B} 97 \mathrm{XD}}=\Delta G_{\omega \mathrm{B} 97 \mathrm{XD} / \mathrm{IEFPCM}}-\Delta E_{\omega \mathrm{B} 97 \mathrm{XD} / \mathrm{IEFPCM}}+$ $\Delta E_{\mathrm{DPLNO}-\mathrm{CCSD}(\mathrm{T})}+\mathrm{SS}$. All ORCA and Gaussian calculations were performed on the Norwegian supercomputer Stallo at UiT, whereas GRRM calculations were performed on the computer cluster at ICIQ. More information on the computational details and example inputs as well as additional DFT energies are given in the ESI. $\dagger$

\section{Conflicts of interest}

There are no conflicts to declare.

\section{Acknowledgements}

This work has been performed with support from NordForsk (Grant No. 85378), the Research Council of Norway (Centre of Excellence Grant No. 262695, KHH), the Tromsø Research Foundation (Grant No. TFS2016KHH to KHH), and Notur - The Norwegian Metacenter for Computational Science (CPU Grant No. nn9330k to $\mathrm{KHH}$ ) and the Artic Centre for Sustainable Energy (ARC) at UiT (Grant No. 310059). We gratefully acknowledge the Faculty of Science and Technology at UiT for a travel grant to MFO. We thank M. K. Langer for HPLC analysis.

\section{Notes and references}

1 (a) M. Aresta, A. Dibenedetto and I. Tommasi, Energy Fuels, 2001, 15, 269-273; (b) M. Mikkelsen, M. Jørgensen and F. C. Krebs, Energy Environ. Sci., 2010, 3, 43-81; (c) Q. Liu, L. Wu, R. Jackstell and M. Beller, Nat. Commun., 2015, 6, 5933, DOI: 10.1038/ncomms6933.

2 G. A. Olah, G. K. S. Prakash and A. Goeppert, J. Am. Chem. Soc., 2011, 133, 12881-12898.

3 For selected reviews on valorisation of $\mathrm{CO}_{2}$, see: (a) M. Aresta, A. Dibenedetto and A. Angelini, Chem. Rev., 2014, 114, 17091742; (b) R. R. Shaikh, S. Pornpraprom and V. D'Elia, ACS Catal., 2018, 8, 419-450.

4 For a review on transition metal-catalysed $\mathrm{C}-\mathrm{C}$ bond forming reactions involving $\mathrm{CO}_{2}$, see: A. Tortajada, F. JuliáHernández, M. Börjesson, T. Moragas and R. Martin, Angew. Chem., Int. Ed., 2018, 57, 15948-15982.

5 (a) J. Vaitla, Y. Guttormsen, J. K. Mannisto, A. Nova, T. Repo, A. Bayer and K. H. Hopmann, ACS Catal., 2017, 7, 7231-7244; (b) M. Obst, L. Pavlovic and K. H. Hopmann, J. Organomet. Chem., 2018, 864, 115-127; (c) L. Pavlovic, J. Vaitla, A. Bayer and K. H. Hopmann, Organometallics, 2018, 37, 941-948.

6 (a) T. Ohishi, L. Zhang, M. Nishiura and Z. Hou, Angew. Chem., Int. Ed., 2011, 50, 8114-8117; (b) H. Ohmiya, M. Tanabe and M. Sawamura, Org. Lett., 2011, 13, 10861088; (c) M. Juhl, S. L. R. Laursen, Y. Huang, D. U. Nielsen, K. Daasbjerg and T. Skrydstrup, ACS Catal., 2017, 7, 13921396.

7 (a) R. D. Grigg, J. W. Rigoli, R. V. Hoveln, S. Neale and J. M. Schomaker, Chem.-Eur. J., 2012, 18, 9391-9396; (b) T. Mita, K. Michigami and Y. Sato, Org. Lett., 2012, 14, 3462-3465; (c) M. Yonemoto-Kobayashi, K. Inamoto, Y. Tanaka and Y. Kondo, Org. Biomol. Chem., 2013, 11, 3773-3775; (d) T. Mita, M. Sugawara, K. Saito and Y. Sato, Org. Lett., 2014, 16, 3028-3031; (e) M. Yonemoto-Kobayashi, K. Inamoto and Y. Kondo, Chem. Lett., 2014, 43, 477-479; (f) X. Frogneux, N. von Wolff, P. Thuery, G. Lefevre and T. Cantat, Chem. - Eur. J., 2016, 22, 2930-2934.

8 For selected examples on Cu-catalysed/initiated decarboxylation, see: (a) T. Cohen and R. A. Schambach, J. Am. Chem. Soc., 1970, 92, 3189-3190; (b) O. Toussaini, P. Capdevielle and M. Maumy, Tetrahedron, 1984, 17, 32293233; (c) L. J. Gooßen, W. R. Thiel, N. Rodriguez, C. Linder and B. Melzer, Adv. Synth. Catal., 2007, 349, 2241-2246; (d) L. J. Gooßen, N. Rodriguez, C. Linder, P. P. Lange and A. Fromm, ChemCatChem, 2010, 2, 430-442.

9 For a selected review on borane-mediated hydroboration of olefins, see: Selective Hydroboration and Synthetic Utility of Organoboranes Thus Obtained, A. Suzuki and R. S. Dhillon, Top. Curr. Chem., 1986, 130, 23-88.

10 The selectivity of hydroboration is substrate dependent. For selected examples on borane-mediated hydroboration of $\beta$ substituted styrenes, see: (a) H. C. Brown, P. K. Jadhav and A. K. Mandal, J. Org. Chem., 1982, 47, 5074-5083; (b) 
H. C. Brown, D. J. Nelson and C. G. Scouten, J. Org. Chem., 1983, 48, 641-643; (c) H. C. Brown and J. Chandrasekharan, J. Org. Chem., 1983, 48, 644-648; (d) H. C. Brown, J. V. N. V. Prasad and S. H. Zee, J. Org. Chem., 1986, 51, 439-445; (e) G. Erker and R. Aul, Chem. Ber., 1991, 124, 1301-1310; (f) J. M. Clay and E. Vedejs, J. Am. Chem. Soc., 2005, 127, 5766-5767; (g) P. Moquist, G.-Q. Chen, C. Muck-Lichtenfeld, K. Bussmann, C. G. Daniliuc, G. Kehr and G. Erker, Chem. Sci., 2015, 6, 816-825.

11 For selected examples on borane-mediated hydroboration of allenes, see:(a) H. C. Brown, R. Liotta and G. W. Kramer, J. Am. Chem. Soc., 1979, 101, 2966-2970; (b) K. K. Wang, Y. G. Gu and C. Liu, J. Am. Chem. Soc., 1990, 112, 44244431; (c) S.-C. Hung, Y.-F. Wen, J.-W. Chang, C.-C. Liao and B.-J. Uang, J. Org. Chem., 2002, 67, 1308-1313; (d) L. Yang, Z. Lin, S.-H. Huang and R. Hong, Angew. Chem., Int. Ed., 2016, 55, 6280-6284; (e) T. Suto, Y. Yanagita, Y. Nagashima, S. Takikawa, Y. Kurosu, N. Matsuo, T. Sato and N. Chida, J. Am. Chem. Soc., 2017, 139, 2952-2955; (f) Y. Nagashima, K. Sasaki, T. Suto, T. Sato and N. Chida, Chem.-Asian J., 2018, 13, 1024-1028.

12 For a review on asymmetric hydroborations using (-)-isopinocampheylborane, see: M. Srebnik and P. V. Ramachandran, Aldrichimica Acta, 1987, 20, 9-24.

13 Related chiral organolithium reagents racemize above $-78{ }^{\circ} \mathrm{C}$, see: (a) Stereochemical Aspects of Organolithium Compounds, ed. R. E. Gawley, Verlag Helvetica Chimica Acta, Postfach, CH-8042 Zürich, Switzerland, 2010, ISBN: 978-3-906-39061-1; (b) A. Basu and S. Thayumanavan, Angew. Chem., Int. Ed., 2002, 41, 716-738; (c) H. J. Reich, J. Org. Chem., 2012, 77, 5471-5491.

14 S. Maeda, K. Ohno and K. Morokuma, Phys. Chem. Chem. Phys., 2013, 15, 3683-3701.

15 For a discussion of feasible barriers at different temperatures, see : H. Ryu, J. Park, H. K. Kim, J. Y. Park,
S.-T. Kim and M.-H. Baik, Organometallics, 2018, 37, 32283239.

16 H. D Velázquez, Z.-H. Wu, M. Vandichel and F. Verpoort, Catal. Lett., 2017, 147, 463-471.

17 R. Kuniyil and F. Maseras, Theor. Chem. Acc., 2017, 136, 65. 18 J.-D. Chai and M. Head-Gordon, Phys. Chem. Chem. Phys., 2008, 10, 6615-6620.

19 Gaussian 16, Revision B.01, M. J. Frisch, G. W. Trucks, H. B. Schlegel, G. E. Scuseria, M. A. Robb, J. R. Cheeseman, G. Scalmani, V. Barone, G. A. Petersson, H. Nakatsuji, X. Li, M. Caricato, A. V. Marenich, J. Bloino, B. G. Janesko, R. Gomperts, B. Mennucci, H. P. Hratchian, J. V. Ortiz, A. F. Izmaylov, J. L. Sonnenberg, D. WilliamsYoung, F. Ding, F. Lipparini, F. Egidi, J. Goings, B. Peng, A. Petrone, T. Henderson, D. Ranasinghe, V. G. Zakrzewski, J. Gao, N. Rega, G. Zheng, W. Liang, M. Hada, M. Ehara, K. Toyota, R. Fukuda, J. Hasegawa, M. Ishida, T. Nakajima, Y. Honda, O. Kitao, H. Nakai, T. Vreven, K. Throssell, J. A. Montgomery, Jr., J. E. Peralta, F. Ogliaro, M. J. Bearpark, J. J. Heyd, E. N. Brothers, K. N. Kudin, V. N. Staroverov, T. A. Keith, R. Kobayashi, J. Normand, K. Raghavachari, A. P. Rendell, J. C. Burant, S. S. Iyengar, J. Tomasi, M. Cossi, J. M. Millam, M. Klene, C. Adamo, R. Cammi, J. W. Ochterski, R. L. Martin, K. Morokuma, O. Farkas, J. B. Foresman, and D. J. Fox, Gaussian, Inc., Wallingford CT, 2016.

20 Y. Guo, C. Riplinger, U. Becker, D. Liakos, Y. Minenkov, L. Cavallo and F. Neese, J. Chem. Phys., 2018, 148, 011101.

21 (a) F. Neese, The ORCA program system, Wiley Interdiscip. Rev.: Comput. Mol. Sci., 2012, 2(1), 73-78; (b) F. Neese, Software update: the ORCA program system, version 4.0, Wiley Interdiscip. Rev.: Comput. Mol. Sci., 2017, 8(1), 1327.

22 (a) K. H. Hopmann, Organometallics, 2016, 35, 3795-3807; (b) C. J. Cramer, Essentials of Computational Chemistry: Theories and models, Wiley, 2004, p. 379. 